\title{
Small and Medium Enterprises (SMEs) Financing in Bangladesh: A Review of Literature
}

\author{
K. M. Anwarul Islam ${ }^{1}$ \\ Md. Rezaul Karim Miajee ${ }^{1}$ \\ ${ }^{1}$ Department of Business Administration, The Millennium University, Dhaka, Bangladesh
Correspondence: Department of Business Administration, The Millennium University, Dhaka, Bangladesh
}

Received: November 21, $2017 \quad$ Accepted: November 23, $2017 \quad$ Online Published: January 7, 2018

\begin{abstract}
The paper has talked about writing accord among approach creators, financial specialists, and business specialists that small and medium enterprise (SMEs) are drivers of monetary development. A sound SME segment contributes unmistakably to the economy through making greater work openings, creating higher generation volumes, expanding sends out and presenting advancement and enterprise skills. The dynamic job of SMEs in creating nations safeguards them as motors through which the development targets of creating nations can be accomplished.
\end{abstract}

Keywords: SMEs, Policy Makers, Economists. .

\section{Introduction}

Regarding the SME area of Bangladesh, remote and national specialists attempted a few examinations. A portion of the eminent ones are:

Scientist sees that the 50.53 percent of SMEs have no entrance to formal wellspring of back. Just 35.79 percent of SMEs appreciate unhindered access to the formal credit. The rest (13.68 percent) of them have confined access to the formal credit. Bank credit is utilized by little level of business visionaries and gives financing of commonly fewer than 20 percent of their aggregate cost. Greater part of the SMEs (59.6 percent) looks for fund for their working capital needs from banks, albeit just a half-of them get advance from banks.

In an investigation Micro Industries Development Assistance and Services (2004) recognizes that wellsprings of back are generally loved ones if there should arise an occurrence of SMEs. Miniaturized scale Industries Development Assistance and Services (MIDAS) recognized store wellsprings of SMEs, which are as per the following:

Researcher observes that the 50.53 percent of SMEs have no access to formal source of finance. Only 35.79 percent of SMEs enjoy unrestricted access to the formal credit. The rest (13.68 percent) of them have restricted access to the formal credit. Bank credit is used by small percentage of entrepreneurs and provides financing of generally less than 20 percent of their total outlay. Majority of the SMEs (59.6 percent) seek finance for their working capital needs from banks, although only a half-of them get loan from banks.

In a study Micro Industries Development Assistance and Services (2004) identifies that sources of finance are mostly friends and family members in case of SMEs. Micro Industries Development Assistance and Services (MIDAS) identified fund sources of SMEs, which are as follows:

Sources of Fund Percentage

Informal sector $41 \%$ 
Family members $20 \%$ (interest free)

$4 \%$ (with interest)

NGO $17 \%$

Bank $18 \%$

\section{Review of Literature}

Analyst indicates out that due the absence of national quality approach and sufficient emotionally supportive network, and furthermore the absence of validity of the quality accreditation specialist, SMEs of Bangladesh have neglected to guarantee the nature of items and administrations both in residential and universal markets. He additionally contends that entrance to back wins as a standout amongst the most critical issues for the SMEs in Bangladesh. Absence of contributing or working supports stays as a standout amongst the most conspicuous whines of all the SMEs in Bangladesh.

Analyst sees that the smaller scale undertaking area itself is a subset of casual economy. These self-possessed little endeavors in both urban and provincial zones are not enlisted or required to be enrolled with any tax assessment or administrative bodies. They are not secured by uniform directions. The principle highlights of the casual area are simplicity of passage, independent work, little scale creation, work escalated work, absence of access to sorted out business sectors, and absence of access to conventional types of credit because of supply-shortfalls and mind-boggling expense of getting. As little in size, small scale ventures frequently utilize under 10 individuals, who are normally the business visionaries' relatives, and can be based at or out of their home. Smaller scale endeavors are regularly the single wellspring of family pay of the poor business people. In view of their arrangement with the casual area with failure to give insurances, the smaller scale ventures confront genuine troubles in acquiring credit from the formal managing an account framework. Once more, as they are exceptionally defenseless against dangers, the neighborhood moneylenders, companions and even relatives in numerous cases demonstrate hesitance to give or loan them cash. These assistance keep denied the miniaturized scale undertaking segment from getting money related help both from formal saving money framework and from the casual credit showcase. All the more imperatively, business banks are once in a while intrigued to give start-up capital. On the off chance that they do that, is exorbitantly specific.

The reasons that make the formal banks hesitant to loan to smaller scale undertakings are abridged by Researcher as:

a) Lending to little ventures is seen as extremely hazardous. The vulnerabilities that confront a little industry, the high death rate, the powerlessness to advertise changes, and to monetary variances, make banks hesitant to manage these customers. Non-installment, or even postponed installment, by a couple of real customers can cause the crumple of an independent venture. The death rate of independent companies is surely high.

b) Parallel to the hesitance of banks to loan to little endeavors is the hesitance of these undertakings to get from banks. The authoritative and expensive conventions of acquiring bank back, especially the time and printed material included, are an impressive hindrance to littler organizations.

c) There is an unmistakable institutional inclination with respect to banks towards loaning to the bigger corporate segment. Much of the time there are interfaces in directorships, joint proprietorships and different other normal money related dealings among banks and the vast undertakings and naturally this prompts inclination for guiding account to these borrowers.

d) The managerial expenses of loaning to little undertakings are high, which cuts profound into the benefit of such exchanges for loaning organizations. This is without a doubt the case and has been borne out in studies.

e) Small endeavors can't, or reluctant, to display full bookkeeping records and other documentation called for by banks. As a rule such records simply don't exist, making examination of credit applications troublesome. 
f) Usually such little borrowers can't give the guarantee and security requested by loaning banks and different establishments previously favoring advances.

g) Enterprises in the "casual division" coming up short on any lawful status confront much more noteworthy issues in acquiring money.

So there is dependably an extensive hole between the interest and supply of assets for the task and advancement of individual smaller scale undertakings and the miniaturized scale endeavor division in general.

Specialist saw that accessibility of back is a noteworthy limitation to arrangement and development of SMEs in Bangladesh. Banks are hesitant to extend their SME credit portfolio since they don't consider SME loaning an alluring and gainful endeavor. This is so in light of the fact that SMEs are viewed as high hazard borrowers in view of their low capitalization, deficient resources and their failure to conform to security necessities of the banks.

Authoritative expenses are likewise higher on the grounds that close checking and supervision of the SME activity winds up essential.

Analyst expresses that there is an issue of loan fee charged by banks and money related establishments for SME fund. Regularly it is contended that the financing cost on SME credits is too high and should be brought down. Under the changed loan fee routine national bank's intercession to diminish financing cost for a specific part won't be all together and include the danger of being translated as a retrograde strategy. For business people, however the supply of and access to back is imperative, the expense of store is additionally a factor for their maintainability and development. The banks and money related establishments ought to consider the way that on the off chance that the rate of premium is too high, the gainfulness of business visionaries, particularly for those of the inventive activities will be unfavorably influenced. In an examination about SME area of Bangladesh Specialist expressed credit requirements are one of the real issues of Bangladeshi SMEs. Scientist features that with regards to Bangladesh SMEs are portrayed by Low capitalization and constrained resources, geological decent variety and high mortality, poor credit information, extremely restricted access to formal wellspring of credit, money force in exchanges, exceptionally restricted record keeping propensity, poor budgetary divulgence because of duty issues. High hazard recognition has prompted high getting expenses.

Analyst makes reference to that Small and Medium Enterprises are the foundation of the economy in nations like Bangladesh. SMEs experience the ill effects of regular requirements, for example, absence of capital, challenges in getting crude materials, absence of access to significant business data, low innovative abilities, issues caused by bulky and exorbitant bureaucratic techniques, and strategies and controls that create advertise contortions. Notwithstanding, with legitimate household strategy bolster from the administration, and an eye towards worldwide market patterns, SMEs can assemble limit and receive the benefits of globalization.

Researcher recognizes that banks as a rule don't express enthusiasm towards SME financing. The explanation for this conservativeness is higher operational cost, less return and high hazard related with the SME financing. Because of little advance size the operational expense is higher and they require serious checking and supervision. The fundamental explanation behind higher hazard is that the little and medium business people are profoundly improbable to conform to the insurance prerequisites as commonly they don't have ardent properties. With the reason of insurance here and there banks and non-bank monetary organizations are hesitant to back SMEs.

Bangladesh Bank Report (2008) says, the key explanations for the SMEs are not going into assembling but rather are monetary obliges, horrid condition of utilities, innovation and arrangement segregations. Then again, Bank and others money related organizations for the most part incline toward vast undertaking customers on account of lower progress costs, and more prominent accessibility of security. 
The SMEs additionally fall outside the compass of small scale back plans, and in this way are constrained to rely upon formal wellsprings of assets at a lot higher financing costs, the Bangladesh Bank report said. The BB report, notwithstanding, said that other interrelated issues like deficiency of short and long haul fund, absence of present day innovation and absence of limited time bolster administrations are real deterrents in the method for advancement of the SMEs part. Higher development of the Small and Medium Enterprises (SMEs) can push slice destitution to a tasteful dimension by dispensing with different biases against work concentrated and making occupations for the gifted labor in the SME division.

Researcher makes reference to that the microfinance business in Bangladesh has achieved a develop organize in the course of the most recent three decades. Amid this time, Micro Finance Industry (MFIs) has made numerous business visionaries and a substantial segment of them are ladies. On the off chance that we fundamentally break down the endeavor scene of a Least Develop Countries (LDCs), we will discover there are five layers of the pyramid. At the base of the pyramid smaller scale business or miniaturized scale undertaking is found, which establish $65-75 \%$ of the aggregate market, private companies catch $20 \%$ piece of the pie, medium organizations cover $5-10 \%$, vast organizations cover $0.9 \%$ and corporate and multinationals cover $0.1 \%$ of the aggregate piece of the pie. The base customers of Micro-business of pyramid are financed by the MFIs. The objective customers of standard monetary organizations like banks and NBFIs are the main two layers of the pyramid, which comprise of vast organizations, corporate and multinationals. In any case, the center two layers of the pyramid where little and medium organizations are found are typically undiscovered both by the standard money related establishments and furthermore the MFIs. This gathering has been named the missing center. To cross over any barrier among microfinance and SME financing, this missing center is to be tended to by both the standard monetary establishments and MFIs. The banks and NBFIs should downscale their SME financing exercises in a way that addresses in any event the upper bit of the missing center. So that there will be an extension between the customers of base layer of the pyramid and upper layer and there will be no hole. In the event that the missing center could be disposed of by retaining them through financing by both standard money related foundations and MFIs then there will be no hole and when the undertakings of microfinance customers extended then these endeavors could be connected with standard budgetary establishments.

\section{Conclusion}

Specialist sees that SMEs move in little scale generation requiring less capital and taking into account the household request. Because of its size, SMEs are generally less proficient than bigger organizations. SMEs in their interest to be more aggressive regarding proficiency and efficiency need to secure a la mode innovation to encourage smoother forms and to update the aptitudes of the workforce with the end goal to develop. Be that as it may, challenges in acquiring money related help and administrations due to inflexible necessities and broad printed material oblige the general extension designs of SMEs. Scientist has called attention to a few disadvantages of SME advances. SMEs are high hazard borrowers as a result of their powerlessness to meet with the guarantee prerequisites of the banks. Financiers issue advances dependent on the responsibility for property as insurance chance. So if the SMEs can't reimburse the obligation, quite possibly the bank will take responsibility for resource. For organizations that are not performing admirably, inferable from the reimbursement plans, SME advances make a weight for them as opposed to helping them to develop. Financing costs of SME credits are high in contrast with general advance.

\section{References}

Beck, T. et. Al (2009). Bank Financing for SMEs: Evidence across Countries and Bank Ownership Types. European Banking Centre Discussion Paper No. 2009-20. Tilburg University. European Banking Centre 
Beck, T. et. al. (2006). Banking SMEs around the World: Lending Practices, Business Models, Drivers and Obstacles

Deakins, D., D. North, R. Baldock and G. Whittam (2008). SMEs’ Access to Finance: Is There Still a Debt Finance Gap? Institute for Small Business \& Entrepreneurship. Belfast, N. Ireland

Dalberg (2011). Report on Support to SMEs in Developing Countries Through Financial Intermediaries.

\section{Copyrights}

Copyright for this article is retained by the author(s), with first publication rights granted to the journal.

This is an open-access article distributed under the terms and conditions of the Creative Commons Attribution license (http://creativecommons.org/licenses/by/4.0/). 